\title{
Bovine tuberculosis in Northern Ireland: Risk factors associated with time from post-outbreak test to subsequent herd breakdown
}

LP Doyle $^{1}$, AW Gordon ${ }^{3}$, DA Abernethy ${ }^{4}, \mathrm{~K}_{\text {Stevens }}^{2}$.

${ }^{1}$ Veterinary Epidemiology Unit, Department of Agriculture and Rural development for Northern Ireland, Dundonald House, Belfast BT4 3SB.

${ }^{2}$ Veterinary Epidemiology, Economics and Public Health Group, Production and Population Health Group, Royal Veterinary College, Hawkshead Lane, North Mymms, Hatfield, Hertfordshire, AL9 7TA, UK.

${ }^{3}$ Agri-Food and Biosciences Institute, Newforge Lane, Belfast, BT9 5PX.

${ }^{4}$ Department of Veterinary Tropical Diseases, Veterinary Faculty, University of Pretoria, South Africa.

Corresponding author: Tel +44 2890765333; fax+44 2890525012.

E-mail address: liam.doyle@dardni.gov.uk

Corresponding address: Veterinary Epidemiology Unit, Department of Agriculture and Rural development for Northern Ireland, Dundonald House, Belfast BT4 3SB.

\begin{abstract}
Compulsory bovine Tuberculosis testing has been implemented since 1959 in Northern Ireland. Initial rapid progress in the eradication of the disease was followed by a situation where disease levels tended to fluctuate around a low level. This study explores recrudescence of bovine tuberculosis (bTB) in Northern Ireland herds by
\end{abstract}


assessing risk factors associated with time from the six-month post-outbreak skin test until a further herd breakdown. Bovine herds $(\mathrm{n}=3377)$ were recruited in 2002 and 2003 and their survival analysed using Kaplan-Meier survival estimates and a Cox proportional hazards model, with follow-up extending to August 2008. Exclusion criteria applied for study entry were bTB infection in a contiguous herd, changing of post restriction test to one of a higher risk status or chronic infection. Chronic infection was defined as any situation where disclosure preceded the post-outbreak test by two years or more. The application of these exclusion criteria meant that herds recruited to the study were largely cleared of infection and not directly contiguous to other infected herds. Of the 3377 herds 1402 (41.5\%) suffered a further herd breakdown before the end of follow-up. Median survival time was 582 days (interquartile range $=336-1002$ days). Breakdown severity (defined as number of Single Intradermal Comparative Tuberculin Test (SICTT) reactors at disclosure test), local bTB prevalence, herd size and type were identified as significant risk factors $(\mathrm{p}<0.05)$, as was the purchase of higher numbers ( $\mathrm{n}>27$ per year) of cattle. Consistent with other studies this work shows bTB confirmation to not be predicative of a future herd breakdown. This work shows bTB history as not being a risk factor for a future breakdown. This result could be reflective of the exclusion criteria used in the study, which may have selected for incidents where historical status was of less importance.

Key words: Epidemiology, Mycobacterium bovis, breakdown severity, Kaplan-Meier, Cox proportional hazards. 


\section{Introduction}

Tuberculosis in cattle caused by Mycobacterium bovis has a worldwide distribution. Eradication has been largely successful in developed countries, particularly those with no significant wildlife reservoirs (Abernethy et al., 2006). An eradication scheme was introduced in Northern Ireland in 1959 but bovine tuberculosis remains endemic. Peak incidence occurred during the spring of 2003 with a herd incidence of $10.2 \%$ and animal incidence of $0.99 \%$. From 2003 to 2007 Northern Ireland bTB levels dropped yearly to reach a consistent level of herd and animal incidence below $6 \%$ and $0.6 \%$ respectively. This steady state situation remained until autumn 2011 when an increase in both herd and animal incidence reached levels of $7.32 \%$ (herd incidence) and $0.663 \%$ (animal incidence) in 2012. Post the peak levels which occurred in 2012 a consistent reduction in bTB levels have been documented during 2013 (www.dardni.gov.uk; accessed 16/12/2013). These figures are placed in context in Abernethy et al. (2012) where bTB trends are described for the UK and Republic of Ireland in the period 1995 to 2010. It describes a stable situation of very low bTB prevalence in Scotland and over most of the period a rising prevalence in England and Wales. The prevalence in the Republic of Ireland declined while Northern Ireland experienced both a rise and fall.

All Northern Ireland cattle are individually identified and have both lifetime movement and tuberculosis test histories recorded. BTB surveillance of all herds is conducted annually using the Single Intradermal Comparative Tuberculin Test (SICTT) with test frequency increasing when bTB is suspected or proven, or where contiguous herds suffer a breakdown. Upon confirmation of bTB, a herd must enter a cycle of shortinterval ('restricted') tests at sixty day intervals and movement restrictions are only lifted after the herd achieves two consecutive clear SICTT tests. When this herd restriction is removed, freedom to trade is restored but a post-outbreak test after six 
months is required. The aim of this study was to investigate selected factors associated with time from the post-outbreak test to subsequent herd breakdown.

Risk factors associated with bTB herd breakdowns have been extensively researched. These factors include presence of a wildlife source (Griffin et al., 1996; Ó Máirtin et al., 1998; Eves, 1999; Griffin et al., 2005; Reilly and Courtenay, 2007), presence of bTB in contiguous herds (Griffin et al., 1996; Denny and Wilesmith., 1999; White et al., 2013 ), environmental survival of M. bovis (Scanlon and Quinn., 2000; Ramírez-Villaescusa et al., 2010), previous bTB history (Olea-Popelka et al., 2004; Carrique-Mas et al., 2008; White et al., 2013), movement of animals (Carrique-Mas et al., 2008; Johnston et al., 2005; Ramírez-Villaescusa et al., 2010), severity of bTB breakdown (Olea-Popelka et al., 2004; Wolfe et al., 2010; Karolemeas et al., 2011 Gallagher et al., 2013), herd type (Griffin et al. 1993; Ramírez-Villaescusa et al., 2010; Alvarez et al., 2012), herd size (Griffin et al., 1996; Green and Cornell, 2005; Brooks-Pollock et al., 2009, Mill et al., 2011; Gallagher et al., 2013) and bTB confirmation ((Olea-Popelka et al., 2004; Abernethy et al., 2010; Wolfe et al., 2010; Karolemeas et al., 2011; Abernethy et al., unpublished). Confirmation plays an important role in the Northern Ireland bTB testing programme. If bTB is confirmed in a herd the shortest possible restricted period is 120 days while with non-confirmation the shortest possible restricted period is 60 days. 


\section{Materials and methods}

\section{Study design and study population}

A retrospective cohort study was undertaken. The study population comprised all herds with a negative post-outbreak test between January $1^{\text {st }} 2002$ and January $31^{\text {st }} 2004$. This period was chosen so as to avoid the disruption to normal bTB testing patterns associated with the 2001 foot and mouth epidemic. Herds were recruited to the study on the date they completed the clear post-outbreak test. On completion of a clear postoutbreak test these herds had carried out at least two negative herd tests and disclosed no $\mathrm{bTb}$ for a period of at least six months. Thus herds recruited to the study should fall into a subset where bTB internal to the herd is minimised. Exit from the study occurred when the herd suffered a subsequent bTB outbreak event, defined as the first positive SICTT following a negative post-outbreak test or the discovery of a confirmed TB lesion at routine slaughter (LRS). The disclosure date of the positive SICTT or LRS was considered to be the date of the bTB outbreak event, and all variables were related to this time-point. End of follow-up was $15^{\text {th }}$ August 2008 and any herd that had not suffered a herd break down at this point exited the study.

Chronic breakdown herds (i.e. herds where disclosure preceded the post-outbreak test by two years or more) or those located contiguous to another bTB infected herd were excluded from the study. Also excluded from the study were those herds with tests initially set as post-outbreak tests and later re-categorised to a higher risk status.

\section{Data collection and variable definitions}

The identification, movement and test history of all individual bovine animals was extracted from the Animal and Public Health Information System (APHIS) run by the Department of Agriculture and Rural Development for Northern Ireland. Variables included breakdown severity, local prevalence of bTB, herd size, herd type, purchase 
intensity, bTB confirmation, and bTB history of the herd. Breakdown severity was based on the number of standard reactors $(0,1,2-3,4-8,>8)$ as recommended by O'Keeffe et al. (1998) with 0 reactors representing the situation where the first herd level test in a breakdown returns no skin reactors. Local prevalence for bTB was defined as the percentage herd prevalence in the local district council area at the date of the post-restriction herd test. Herd size was the number of cattle tested at the first herd level test in the breakdown. Herd type was either non-dairy or dairy with the latter herds being in possession of a milk licence. Purchase intensity was calculated as the number of cattle purchased into a herd after derestriction divided by the period the herd remained disease free or reached the end of follow up. BTB confirmation was based on finding visible lesions in SICTT reactor animals or obtaining a positive histological or bacteriological examination from a slaughtered animal. Herds were classified as having a history of TB if a SICTT reactor or confirmed LRS occurred in the two years prior to the breakdown.

\section{Data analysis}

Microsoft Access ${ }^{\mathrm{TM}}$ was used for all data manipulation and STATA/IC 10.0 (Stata, College Station, TX) for data analysis. All continuous variables were categorised so as to create categories containing approximately equal numbers of observations. Relevant summary statistics were calculated for each variable. Kaplan-Meier (KM) plots were produced for each variable and logrank tests used to determine whether time to subsequent herd breakdown differed between the levels of each variable (Clark et al., 2003). Univariable and multivariable Cox proportional hazards regression models were used to identify factors significantly associated with time to subsequent herd 
breakdown. Univariable Cox proportional hazard models were created for each variable and the validity of the proportional hazard assumption assessed in two ways. The first was to visually determine whether the plots of $-\log (-\log )$ survival lines were parallel (Bradburn et al., 2003). The second was to incorporate each variable into the model as a time-varying covariate (Dohoo et al., 2003). Following univariable analysis all variables were included in a multivariable Cox regression model using a forward stepwise method. All combinations of two-way interactions were assessed between the significant variables in the final model by forcing these terms into the model. The likelihood ratio test was used to assess whether or not their inclusion improved the overall fit of the model. For all analyses a p-value cut off point of 0.05 was considered significant.

The power (and indeed in some cases validity) of survival analysis is related to the number of events rather than the number of participants (Bradburn et al., 2003). Simulation work has suggested that at least ten events need to be observed for each covariate considered, with anything less leading to problems (Bradburn et al., 2003). In the current study the maximum number of covariates included in the model at any point was 19, so that 190 events (bTB breakdowns) would be required for the study to have sufficient power. As 1402 events were included in the study it is assumed that the study had sufficient power. 


\section{Results}

\section{Time from post-outbreak test to subsequent herd breakdown}

Of the 3377 herds included in the study, 1402 (42\%) experienced a breakdown before the end of the follow-up period. Median length time to breakdown (582 days (IQR 336 - 1002)) for herds disclosing a bTB event was significantly less than the median length of time in the study for those herds with no bTB event (1679 days (IQR 1506 - 1884)) (Kruskal-Wallis equality-of-populations rank test $\chi 2=2103 ; \mathrm{p}<0.001$ ).

Kaplan-Meier curves for all variables are presented in Figures one to seven. Median time to subsequent herd breakdown decreased significantly with increasing breakdown severity (logrank $\mathrm{p}<0.05$; Figure 1), local bTB prevalence (logrank $\mathrm{p}<0.05$; Figure 2), purchase intensity (logrank $\mathrm{p}=<0.05$; Figure 3$)$ and herd size $(\operatorname{logrank} \mathrm{p}<0.05$; Figure 4). Median time to subsequent herd breakdown was significantly less for dairy than non-dairy herds (logrank $\mathrm{p}<0.05$; Figure 5) and for herds in which bTB was confirmed as opposed to those in which it was not confirmed (logrank $\mathrm{p}<0.05$; Figure 6). There was no significant difference in median time to subsequent breakdown of herds with or without a history of bTB $(\operatorname{logrank} p=0.06$; Figure 7$)$.

An assessment of the variables in which basic correlations were examined without taking any account of survival data was carried out. Correlations shown to be significant were herd size and herd type $(\mathrm{p}<0.001)$; bTB confirmation and breakdown severity $(\mathrm{p}<0.001)$ along with herd size and bTB history $(\mathrm{p}<0.001)$. 
All variables except for bTB history were significant in the univariable Cox regression models (Table 1). The final model (Table 2) contained the variables herd size, herd type, local prevalence, breakdown severity and purchase intensity. Time to subsequent breakdown was significantly less for dairy herds than non-dairy herds (Hazard Ratio (HR) $1.31,95 \%$ CI 1.16 - 1.49) while time to subsequent breakdown decreased significantly with increasing herd size, breakdown severity and local bTB prevalence. Rate of subsequent breakdown was 3.17 times higher in herds with more than 180 animals compared to herds of 30 animals. For breakdown severity there was no significant difference $(\mathrm{p}=0.582)$ in herd breakdown rate between zero (i.e. an LRS followed by a clear herd SCITT) or one reactor, but thereafter rate of herd breakdown increased with increasing number of reactors. Similarly, there was no significant difference in herd breakdown rate between a local bTB prevalence of less than $9 \%$ or 9 to $12 \%(\mathrm{p}=0.766)$, but thereafter breakdown rate increased significantly with increasing local prevalence. Purchase intensities of between 0.002 to 0.0749 animals per day had a similar effect on the rate of herd breakdown (HR 0.88 (95\% CI 0.73-1.06) HR 0.99 (95\% CI 0.83-1.18)), while a purchase intensity relative to this group of > 0.075 animals per day ( $>27$ animals per year) significantly increased rate of herd breakdown (HR 1.23, 95 \% CI 1.03 - 1.49). No two-way interactions were significantly associated with time to subsequent herd breakdown.

\section{Discussion}

This study and that of Olea-Popelka et al. 2004 are the only studies of which the authors are aware that look at time to herd breakdown, rather than simply determining factors associated with presence of a breakdown following a post-breakdown herd test. While 
many studies have investigated factors associated with herd breakdowns only a few have looked at the impact of particular test types (Green and Cornell, 2005; CarriqueMas et al., 2008). Determination of the risk factors associated with time from postoutbreak test to subsequent herd breakdown has potential to assist in formulation of bTB control policies. We found herd size, breakdown severity, herd type, local prevalence and purchase intensity to be significantly associated with time to subsequent herd breakdown, with hazard of breakdown increasing with increasing herd size, breakdown severity, local bTB prevalence and purchase intensity. In addition, dairy herds experienced a subsequent outbreak significantly sooner than non-dairy herds.

Increasing herd size has consistently been shown to be associated with increased risk of herd breakdown (Griffin et al., 1996; Green and Cornell, 2005; Brooks-Pollock et al., 2009, Mill et al., 2011; Gallagher et al., 2013). In this study increasing herd size has been shown to reduce the time to a subsequent breakdown. This may reflect imperfect specificity of the SICTT (96 - $99 \%$; Monaghan et al., 1994) or could, as described in Denny and Wilesmith, (1999), be related to the greater risk of contact with contiguous herds or with badgers in the area. De La Rua-Domenach et al. (2006) challenged the idea of poor SICTT specificity, pointing out that the lack of visible lesions in some reactors is not necessarily one of poor SICTT specificity but instead reflects inadequate gold standards to determine true infection standards. This idea has also been investigated in Good et al. (2011) where concerns regarding the specificity of the SICTT of single positive animals in the absence of an obvious source of (bTB) infection were perceived as a "false" positive. Good et al. (2011) however concluded that for the Irish bTB eradication programme data presented was consistent with published literature on the sensitivity, specificity and test reliability of the SICTT. Brooks-Pollock 
and Keeling (2009) explicitly connect herd size and disease persistence and point out that many elements intrinsic to large herds such as increased number of movements, larger land coverage, increased environmental contamination and more densely stocked cattle could contribute. Brooks-Pollock and Keeling (2009) and Denny and Wilesmith (1999) point to the risk of bTB in large herds as being multifactorial in nature and probably related to increased scale of operations on these types of holdings.

Increased breakdown severity has been shown by this, and other studies (Olea-Popelka et al., 2004; Wolfe et al., 2010; Karolemeas et al., 2011 Gallagher et al., 2013), to be associated with decreased time to subsequent outbreaks. This could be due to spread of the disease within a herd or to the persistence of factors which led to the initial reactors (Olea-Popelka et al., 2004). Karolemas et al. (2011) states that the relative contribution of within-herd persistence and re-introduction of infection to the recurrence of breakdowns is not known. It is however suggested that recurrence after a short time period relates to within herd persistence. All herds in this study had negative breakdown and six-month post-restriction tests which should have acted to reduce the significance of bTB 'within herd persistence' though probably not addressing the issue of latently infected animals. This in turn could suggest that the main element driving recurrence and of bTB breakdowns in this study is re-introduction of infection to the herds.

Dairy herds were found to be at higher risk of breakdown than non-dairy herds. Dairy herds have been shown to be an additional risk factor in other work (Griffin et al. 1993; Ramírez-Villaescusa et al., 2010; Alvarez et al., 2012). In the initial analysis it was shown that the type of herd was associated with herd size, with dairy herds being larger. 
This variable however remained significant in the final multivariable model, which included herd size, suggesting that other factors, intrinsic to dairy herds, are associated with the shorter time to breakdown. A possible explanation for this is described in Griffin et al. (1993) where more intensively managed dairy herds were determined to be at a greater risk from tuberculosis than were other herds. Another explanation for increased risk in dairy herds is that dairy cattle reach an older age than cattle intended for meat and so have a longer time to be exposed and infected with bTB (RamírezVillaescusa et al., 2010). Alvarez et al. (2012) determined that dairy herds had a higher risk of bTB compared to other herd types as indicated by larger values of within herd transmission, proportion of outbreaks and proportion of recurrently infected farms. The reasoning given for this finding again relates to management where dairy farms are more likely to have high contact rates, high density and presence of stressors.

Bermingham et al. (2009) investigated genetic susceptibility of the Irish HolsteinFriesian dairy herd. This paper demonstrated that significant genetic variability for susceptibility to confirmed $M$. bovis infection exists. Relative to other cattle in the population the dairy herd has a different genetic background Ramírez-Villaescusa et al. (2010). It is possible that dairy herd genetics could play a role in making this variable significant, though in a Northern Ireland context more work would be required to determine its overall contribution.

One way in which risk of disease could persist is where high bTB prevalence in a locality at the disclosing test is still present when the herd enters the study at its postoutbreak herd test. This possibility was investigated using the variable local prevalence. The results show a threshold level at $12 \%$ prevalence above which the hazard of a future herd breakdown increases as bTB prevalence increases. This may indicate that a 
certain pivotal concentration of local infection leads to acceleration in number of herd breakdowns. Denny and Wilesmith (1999) argue that the local factors which influence herd breakdown involve a complex interplay of farm boundaries, neighbours and wildlife. The risk presented within a locality by contiguous herds has been identified in previous work (Griffin et al., 1996; Denny and Wilesmith, 1999; Johnston et al., 2011). Associations between infected wildlife and future herd bTB risk have been demonstrated previously (Griffin et al., 1996; Reilly and Courtenay, 2007) In White et al. (2013) the topic of locality is teased apart to determine the relative importance of bTB farm to farm spread and spread from wildlife. It shows that there is a risk from herds directly contiguous and herds $>25 \mathrm{~m}$ from the farm boundary, which is best explained by an infected wildlife source. The variable used in our study (local prevalence) does not attempt to break the locality effect into its components, however Murphy et al. (2011) point to the fact that cattle act as sentinels for TB in badgers. This means cattle prevalence probably acts as a good proxy for local bTB infection pressure, though how it reflects the components of contiguous or wildlife spread is unknown.

Another risk area for bTB is movement of cattle into a herd. This study design meant that herds were present within the study for variable amounts of time and would thus have purchased varying numbers of cattle. To adjust for this, a variable 'purchase intensity' was used, which is an integration of these two variables into one measurement - number of animals purchased per unit time. In herds with $>27$ animals purchased per year there is an increased hazard of bTB breakdown relative to the baseline level of < 0.73 animals purchased per year. The type of herd from which purchases occurred was not taken into account as it could not be accurately ascertained from the original dataset. 
Increased risk has been shown to be associated with purchasing cattle from herds with a greater than biennial frequency of testing for bTB in the previous eight years (CarriqueMas et al., 2008) and purchasing from markets (Johnston et al., 2005; RamírezVillaescusa et al., 2010) although some authors have produced work which questions risk associated with cattle movement (Griffin et al., 1996; Abernethy et al., 2000). In Green et al. (2008) Great Britain bTB outbreak data for 2004 was used to estimate that $16 \%$ of herd infections were directly related to cattle movements. The idea of herd infection initiated by purchase of infected animals is supported by Berrian et al. (2012). In this work the risk of bTB was determined among animals sold out of herds in the Republic of Ireland (ROI) in 2005. Animals sold out of herds with a bTB episode in 2005 before the episode began had more than twice the odds of developing bTB in the subsequent two years compared to those moving out after the episode. It is also a feature of bTB breakdowns where some are more efficient at onward spread of infection than others. This particular aspect is demonstrated in Gopal et al. (2006) where in the study of 31 herds disclosing bTB in north-east England between January 2002 and June 2004 one source herd was linked to nine of the breakdowns.

A Bovine Tuberculosis Biosecurity Study for County Down, Northern Ireland (O'Hagan et al., unpublished) examined purchase of cattle as a risk factor for a bTB breakdown. It was found that the purchase of store or beef animals in the last 3 years was significantly more common in case farms compared to control farms (adjusted $\mathrm{OR}=4.60 ; 95 \%$ CI 1.61-13.13; $\mathrm{P}=0.003)$. This supports previous research that purchasing, potentially infected, cattle can be associated with an increased risk of bTB breakdown (O'Hagan et al., unpublished). The majority of cattle herds in Northern Ireland do not have adequate facilities to finish all of their animals, instead making use of livestock markets to trade cattle. When purchasing cattle at a market it is not 
presently possible to determine the bTB historical status of the herd selling cattle. This means the buyer can use no element of risk judgement in the purchase of animals, being equally probable to obtain animals from low or high risk sellers.

The bTB history of a herd has been shown in many studies to be a significant risk factor, where a historical bTB episode makes a future one more probable. (Wilesmith and Williams, 1987; Olea-Popelka et al., 2004; Green and Cornell, 2005; Carrique-Mas et al., 2008, Wolfe et al., 2010, Karolemeas et al., 2011). In this study bTB history was not found to be significantly associated with time to subsequent breakdown and given the chronic nature of bTB this is surprising. Dawson et al. (2012) define the causes of recurrent $\mathrm{TB}$ episodes as repeated exposure to infected wildlife vectors, repeated purchase of infected stock and recrudescence of within-herd infection. In Good et al. (2013) full depopulation of high risk bTB herds was compared to depopulation of low risk herds. The risk status given to a herd was based on its bTB history in the previous five years. In the case of the high risk herds a local badger removal policy was implemented. The study determined that there was no substantial difference in future bTB risk between the two groups. Good et al. (2013) thus provides insight into how removal of one of the Dawson et al. (2012) defined causes of recurrent TB episodes can reset the historical status to a lower level. Our study uses a 2 year time period on which to base the bTB history variable, thus categorising herds with a recent breakdown and theoretically at higher risk. Olea-Popelka et al. (2004), found bTB history to significantly increase the hazard of a future bTB breakdown but used a five year period. Carrique-Mas et al. (2008) reported that the reduction in odds of herd breakdown where there was a history of bTB was indistinguishable from an exponential decay distribution. It pointed to the fact that even five years after a herd breakdown there was 
an $\mathrm{OR}=2.9(95 \% \mathrm{CI} 1.11-7.78)$ of a further disease incident relative to a herd which did not have a breakdown. A possible explanation as to why bTB history was found not to be significant in this study is the selection process for herds entering the study. The fact that chronically infected herds and herds with additional risk factors were excluded from the study, may have selected for a type of breakdown in which the historical status was of less importance. Thus given what Dawson et al. (2012) has defined as the causes of recurrent TB episodes selecting herds without additional risk factors may select those in areas where the wildlife vector component is minimal. Also by including herds with a clear post restriction test the recrudescence factor is minimised as these herds have at that point completed three clear herd tests.

Confirmation of bTB post disclosure was shown not to be significant in the final multivariable model. This is a surprising result given that confirmation has an important status in the Northern Ireland eradication and control programme (Abernethy et al., 2006). Also it could be thought that presence of lesions would indicate a longer standing infection and thus increased risk for a herd. However Abernethy et al. (2010) found that neither confirmation of infection at the disclosure test nor subsequently in the breakdown was a statistically significant risk factor. This same result has been reported in other studies (Olea-Popelka et al., 2004; Wolfe et al., 2010; Karolemeas et al., 2011; Abernethy et al., unpublished).

\section{Conclusion}

The original objective of this work was to investigate risk factors affecting the time period from post-outbreak test to a further herd breakdown for Northern Ireland cattle 
herds. The key conclusions reached from this study are that increasing herd size, breakdown severity, local bTB prevalence and purchase level above 27 animals per year are all associated with a decreased time to subsequent outbreak. The study also concludes that dairy herds are associated with a decreased time to subsequent outbreak. Consistent with other studies this work shows bTB confirmation to be not predicative of a future herd breakdown. However, probably due to the selection processes applied to herds for entry to the study bTB history was found not to be a risk factor for a future herd breakdown.

\section{Conflict of Interest}

The authors declare that they are not in a situation of conflicting interests

\section{References}

Abernethy, D.A., Pfeiffer, D.U., Neill, S.D., 2000. Case control study examining the role of livestock markets in the transmission of bovine tuberculosis. In: Thrushfield, M.V., Goodall, E.A. (Eds.), Society for Veterinary Epidemiology and preventative Medicine Proceedings, Edinburgh, 29-31 March 2000, pp. 108-114.

Abernethy, D.A., Denny, G.O., Menzies, F.D., McGuckian, P., Honhold, N., Roberts, A.R., 2006. The Northern Ireland programme for the control and eradication of Mycobacterium bovis. Veterinary Microbiology 112, 231-237 
Abernethy, D.A., Graham, D., Skuce, R., Gordon, A., Menzies, F., Robinson, P., Harwood, R., Clarke, N., 2010. The Bovine tuberculosis eradication scheme. In: proceedings of Society for Veterinary Epidemiology and Preventative Medicine, Nantes, France, 167-173.

Abernethy, D.A., Upton, P., Higgins, I.M., McGrath, G., Goodchild, A.V., Rolfe, S.J., Broughan, J.M., Downs, S.H., Clifton-Hadley, R., Menzies, F.D., de la Rua-Domenech, R., Blissit, M.J., Duignan, A., More, S.J., 2012. Bovine tuberculosis trends in the UK and the Republic of Ireland, 1995-2010. The Veterinary Record, 172, 312-325.

Alvarez, J., Perez, A.M., Bezos, J., Casal, C., Romero, B., Rodriguez-Campos, S., SaezLlorente, J.L., Diaz, R., Carpintero, J., de Juan, L., Dominguez, L., 2012. Eradication of bovine tuberculosis at a herd-level in Madrid, Spain: study of within-herd transmission dynamics over a 12 year period. BMC Veterinary Research 2012, 8:100

Berrian, A.M., O’Keeffe, J., White, P.W., Norris, J., Litt, J., More, S.J., Olea-Popelka, F.J., 2012 Risk of bovine tuberculosis for cattle sold out from herds during 2005 in Ireland. Veterinary Record; 2012. 170(24):620.

Bradburn, M.J., Clark, T.G., Love, S.B., Altman, D.G., 2003. Survival Analysis Part III: Multivariate data analysis - choosing a model and assessing its adequacy and fit. British Journal of Cancer 89, 605-611.

Brooks-Pollock, E., Keeling, M., 2009. Herd size and bovine tuberculosis persistence in cattle farms in Great Britain. Preventative Veterinary Medicine 92, 360-365. 
Carrique-Mas, J.J., Medley, G.F., Green, L.E., 2008. Risks for bovine tuberculosis in British cattle farms restocked after the foot and mouth disease epidemic of 2001. Preventative Veterinary medicine 84, 85-93.

Clark, T.G., Bradburn, M.J., Love, S.B., Altman, D.G., 2003. Survival Analysis Part I: Basic concepts and first analyses. British Journal of Cancer 89, 232-238.

Dawson, K., Stevenson, M., Bosson, M., Sinclair, J., Livingstone, P., 2012. Risk factors for recurrent TB infection in New Zealand: an investigation using time dependant covariates in a Cox proportional hazards regression model. Proceedings of the $13^{\text {th }}$ International Symposium on Veterinary Epidemiology and Economics, http://curis.ku.dk/portal-life/files/40503956/ISVEE_13_2012_book_of_abstracts.pdf

De La Rua-Domenach, R., Goodchild, A.T., Vordermeier, H.M., Hewinson, R.,G., Christiansen, K.,H., Clifton_Hadley, R.,S., 2006. Ante mortem diagnosis of tuberculosis in cattle: a review of the tuberculin tests, gamma-interferon assay and other ancillary diagnostic techniques. Research in Veterinary Science 81, 190-210.

Denny, G.O., Wilesmith, J.W., 1999. Bovine tuberculosis in Northern Ireland: a casecontrol study of herd risk factors. Veterinary Record 144, 305-310.

Dohoo, I., Martin, S.W., Stryhn, H., 2003. Veterinary Epidemiologic Research. AVC Inc., Charlottetown, PEI, Canada, pp. 434-435. 
Eves, J.A., 1999. Impact of badger removal on bovine tuberculosis in east Count Offaly. Irish Veterinary Journal 52, 199-203.

Gallagher, M.J., Higgins, I.M., Clegg, T.A., Williams, D.H., More, S.J., 2013. Comparison of bovine tuberculosis recurrence in Irish herds between 1998 and 2008. Preventative Veterinary Medicine 111 (2013) 237-244.

Good, M., Clegg, T.A., Duignan, A., More, S.J., 2011. Impact of the full herd depopulation policy on the recurrence of bovine tuberculosis in Irish herds, 2003 to 2005. Veterinary Record; 2011. 169(22):581.

Gopal, R., Goodchild, A., Hewinson, G., De La Rua Domenech, R., Clifton-Hadlet, R., 2006. Introduction of bovine tuberculosis to north-east England by bought in cattle. Veterinary Record (2006) 159, 265-271.

Green, D.M., Kiss, I.Z., Mitchell, A.P., Kao, R.R., 2008. Estimates for local and movement-based transmission of bovine tuberculosis in British cattle. Proceedings of the Royal Society B (2008) 275, 1001-1005.

Green, L.E., Cornell, S.J., 2005. Investigations of cattle herd breakdowns with bovine tuberculosis in four counties of England and Wales using VETNET data. Prev. Vet. Med. 70, 293-311.

Griffin, J.M., Hahesy, T., Lynch, T., Salman, M.D., McCarthy, J., Hurley, T., 1993. The association of cattle husbandry practices, environmental factors and farmers 
characteristics with the occurrence of chronic bovine tuberculosis in the Republic of Ireland. Preventative Veterinary Medicine 17, 145-160.

Griffin, J.M., Martin, S.W., Thorburn, M.A., Eves, J.A., Hammond, R.F., 1996. A casecontrol study on the association of selected risk factors with the occurrence of bovine tuberculosis in the Republic of Ireland. Preventative Veterinary medicine 27, 75-87.

Griffin, J.M., Williams, D.H., Kelly, G.E., Clegg, T.A., O’Boyle, I., Collins, J.D., More, S.J., 2005. The impact of badger removal on the control of tuberculosis in cattle herds in Ireland. Preventative Veterinary medicine 67, 237-266.

Johnston, W.T., Gettinby, G., Cox, D.R., Bourne, F.J., Clifton-Hadley, R., Fevre, A.M. le., McInerney, J.P., Mitchell, A., Morrison, W.I., Woodroffe, R., 2005. Herd-level risk factors associated with tuberculosis breakdowns among cattle in England before the 2001 foot-and-mouth disease epidemic. Biology letters Vol. 1 No. 1 pp. 53-56.

Johnston, W.T., Vial, F., Gettinby, G., Bourne, F.J., Clifton-Hadley, R., Cox, D.R., Crea, P., Donnely, C.A., McInerney, J.P., Mitchell, A., Morrison, W.I., Woodroffe, R., 2011. Herd-level risk factors of bovine tuberculosis in England and Wales after the 2001 foot-and-mouth disease epidemic. International Journal of Infectious Diseases 15 (2011) e833-e840.

Karolemeas, K., McKinley, T.J., Clifton-Hadley, R.S., Goodchild, A.V., 
Mitchell, A., Johnston, W.T., Conlan, A.J.K., Donnelly, C.A., Wood, J.L.N., 2011. Recurrence of bovine tuberculosis breakdowns in Great Britain: Risk factors and prediction. Preventative Veterinary Medicine 102, 22-29.

Mill, A.C., Rushton, S.P., Shirley, M.D.F., Murray, A.W.A., Smith, G.C., Delahay, R.J., McDonald, R.A., 2011. Farm-scale factors for bovine tuberculosis incidence in cattle herds during the Randomised Badger Culling Trial. Epidemiology and Infection; 2012. 140(2):219-230.

Monaghan, M.L., Doherty, M.L., Collins, J.D., Kazda, J.F., Quinn, P.J., 1994. The tuberculin test. Veterinary Microbiology 40, 111-124.

O'Keefe, J.J., White, P.W., Martin, S.W., 1998. Episode classification bovine tuberculosis 1989 to 1997. In: Selected Papers. Tuberculosis Investigation Unit, University College Dublin, pp. 30-44.

Olea-Popelka, F.J., White, P.W., Collins, J.D., O’Keefe, J., Kelton, D.F., Martin, S.W., 2004. Breakdown severity during a bovine tuberculosis episode as a predictor of future herd breakdowns in Ireland. Preventative Veterinary medicine 63, 163-172.

Ó Máirtin, D., Williams, D.H., Dolan, L., Eves, J.A., Collins, J.D., 1998. The influence of selected herd factors and a badger-intervention tuberculosis-control programme on the risk of a herd-level trade restriction to a bovine population in Ireland. Preventative Veterinary Medicine 35, 79-90. 
Reilly, L.A., Courtenay, O., 2007. Husbandry practices, badger sett density and habitat composition as risk factors for transient and persistent bovine tuberculosis on UK cattle farms. Preventative Veterinary Medicine 80, 129-142.

Ramírez-Villaescusa, A.M., Medley, G.F., Mason, S., Green, L.E., 2010. Risk factors for herd breakdown with bovine tuberculosis in 148 cattle herds in the south west of England. Preventative Veterinary Medicine 95, 224-230.

Scanlon, M.P., Quinn, P.J., 2000. The survival of Mycobacterium bovis in sterilized cattle slurry and its relevance to the persistence in the environment. Irish Veterinary Journal Vol. 53 No. 8, pp 412-415.

Wilesmith, J., Williams, D., 1987. Observations on the incidence of herds with nonvisible lesioned tuberculin test reactors in south-west England. Epidemiol. Infect. 99, 173-178.

White, P.W., Martin, S.W., De Jong, M.C.M., O’Keeffe, J.J., More, S.J., Frankena, K., 2013. The importance of 'neighbourhood' in the persistence of bovine tuberculosis in Irish cattle herds. Preventative Veterinary Medicine 110, 346-355.

Wolfe, D.M., Berke, O., Kelton, D.F., White, P.W., More, S.J., O’Keefe, J., Martin, S.W., 2010. From explanation to prediction: Amodel for recurrent bovine tuberculosis in Irish cattle herds. Preventative Veterinary medicine 94 (2010) 170-177. 


\section{Figures and Tables}

Figures

Figure 1 Box plot showing survival times in herds which did not experience a bTB event (0) and herds which experience the bTB event (1).

Figure 2 Kaplan-Meier curves calculated on time intervals from post-outbreak test to disease incident and stratified by increasing severity of disclosure bTB test.

Figure 3 Kaplan-Meier curves calculated on time intervals from post-outbreak test to disease incident and stratified by increasing levels of local prevalence for bTB.

Figure 4 Kaplan-Meier curves calculated on time intervals from post-outbreak test to disease incident and stratified by increasing levels of purchase intensity.

Figure 5 Kaplan-Meier curves calculated on time intervals from post-outbreak test to disease incident and stratified by whether a herd is non-dairy or dairy in nature.

Figure 6 Kaplan-Meier curves calculated on time intervals from post-outbreak test to disease incident and stratified by increasing herd size. 


\section{Tables}

Table 1 Univariable Cox regression showing association between selected variables and TB herd breakdowns of 3377 herds in Northern Ireland between January 2002 and January 2004.

Table 2 Table showing multivariable hazard ratios, significance levels and confidence intervals for the described variables in 3377 herds entered into the survival study from $1^{\text {st }}$ of January 2002 to $1^{\text {st }}$ of January 2004. 
Table 1. Univariable Cox regression showing association between selected variables and TB herd breakdowns of 3377 herds in Northern Ireland between January 2002 and January 2004.

\begin{tabular}{|c|c|c|c|c|}
\hline Variable & Exposure level & Hazard Ratio & $\begin{array}{l}\text { 95\% C.I. of } \\
\text { Hazard Ratio }\end{array}$ & P-value \\
\hline Herd Size & $\begin{array}{c}<30 \\
30-59 \\
60-99 \\
100-179 \\
>=180\end{array}$ & $\begin{array}{l}1.00 \\
1.50 \\
2.17 \\
2.86 \\
3.99\end{array}$ & $\begin{array}{c}- \\
1.23-1.83 \\
1.80-2.62 \\
2.38-3.44 \\
3.30-4.82\end{array}$ & $\mathrm{P}<0.005$ \\
\hline Breakdown Severity & $\begin{array}{c}0 \\
1 \\
2 \text { to } 3 \\
4 \text { to } 8 \\
>8\end{array}$ & $\begin{array}{l}1.00 \\
0.93 \\
1.25 \\
1.48 \\
1.96\end{array}$ & $\begin{array}{c}- \\
0.80-1.08 \\
1.07-1.46 \\
1.25-1.75 \\
1.64-2.33\end{array}$ & $\mathrm{P}<0.005$ \\
\hline $\begin{array}{c}\text { Local Prevalence } \\
(\%)\end{array}$ & $\begin{array}{c}<9 \\
9 \text { to }<12 \\
12 \text { to }<15 \\
15 \text { to }<18 \\
>18\end{array}$ & $\begin{array}{l}1.00 \\
1.06 \\
1.40 \\
1.65 \\
1.53\end{array}$ & $\begin{array}{c}- \\
0.88-1.26 \\
1.18-1.66 \\
1.38-1.98 \\
1.26-1.85\end{array}$ & $\mathrm{P}<0.005$ \\
\hline $\begin{array}{l}\text { Purchase intensity } \\
\text { (Animals } \\
\text { per day) }\end{array}$ & $\begin{array}{c}<0.002 \\
0.002 \text { to }<0.0075 \\
0.0075 \text { to }<0.025 \\
0.025 \text { to }<0.075 \\
>=0.075\end{array}$ & $\begin{array}{l}1.00 \\
0.93 \\
0.89 \\
1.07 \\
1.38\end{array}$ & $\begin{array}{c}- \\
0.77-1.12 \\
0.74-1.06 \\
0.90-1.28 \\
1.16-1.64\end{array}$ & $\mathrm{P}<0.005$ \\
\hline Herd Type & $\begin{array}{l}\text { Non-Dairy } \\
\text { Dairy }\end{array}$ & $\begin{array}{l}1.00 \\
1.78\end{array}$ & $\begin{array}{c}- \\
1.60-1.98\end{array}$ & $\mathrm{P}<0.005$ \\
\hline BTB Confirmation & $\begin{array}{c}\text { TB not } \\
\text { confirmed } \\
\text { TB confirmed }\end{array}$ & $\begin{array}{l}1.00 \\
1.22\end{array}$ & $\begin{array}{c}- \\
1.10-1.36\end{array}$ & $\mathrm{P}<0.005$ \\
\hline TB History & $\begin{array}{l}\text { No } \\
\text { Yes }\end{array}$ & $\begin{array}{l}1.00 \\
1.11\end{array}$ & $\begin{array}{c}- \\
0.99-1.23\end{array}$ & $\mathrm{P}=0.064$ \\
\hline
\end{tabular}


Table 2. Table showing multivariable hazard ratios, confidence intervals and significance levels for the described variables in 3377 herds entered into the survival study from $1^{\text {st }}$ of January 2002 to $1^{\text {st }}$ of January 2004.

\begin{tabular}{|c|c|c|c|c|}
\hline Variable & Variable level & $\begin{array}{c}\text { Hazard } \\
\text { Ratio }\end{array}$ & $\begin{array}{l}\text { 95\% C.I. of } \\
\text { Hazard } \\
\text { Ratio }\end{array}$ & P-Value \\
\hline \multirow[t]{5}{*}{ Herd Size } & $<30$ & 1.00 & - & - \\
\hline & $30-59$ & 1.44 & $1.18-1.76$ & $<0.005$ \\
\hline & $60-99$ & 1.91 & $1.57-2.32$ & $<0.005$ \\
\hline & $100-179$ & 2.43 & $2.00-2.97$ & $<0.005$ \\
\hline & $>=180$ & 3.17 & $2.56-3.92$ & $<0.005$ \\
\hline \multirow[t]{5}{*}{ Local Prevalence $(\%)$} & $<9$ & 1.00 & - & - \\
\hline & 9 to $<12$ & 1.03 & $0.86-1.23$ & 0.766 \\
\hline & 12 to $<15$ & 1.40 & $1.18-1.67$ & $<0.005$ \\
\hline & 15 to $<18$ & 1.63 & $1.36-1.96$ & $<0.005$ \\
\hline & $>18$ & 1.78 & $1.47-2.17$ & $<0.005$ \\
\hline \multirow[t]{2}{*}{ Herd Type } & Non-Dairy & 1.00 & - & - \\
\hline & Dairy & 1.31 & $1.16-1.49$ & $<0.005$ \\
\hline \multirow[t]{5}{*}{ Breakdown Severity } & 0 & 1.00 & - & - \\
\hline & 1 & 1.04 & $0.90-1.21$ & 0.582 \\
\hline & 2 to 3 & 1.19 & $1.02-1.39$ & 0.025 \\
\hline & 4 to 8 & 1.27 & $1.07-1.51$ & 0.006 \\
\hline & $>8$ & 1.50 & $1.25-1.79$ & $<0.005$ \\
\hline \multirow[t]{2}{*}{ Purchase Intensity } & $<0.002$ & 1.00 & - & - \\
\hline & 0.002 to $<0.0075$ & 0.88 & $0.73-1.06$ & 0.170 \\
\hline \multirow{3}{*}{$\begin{array}{l}\text { (Animals } \\
\text { per day) }\end{array}$} & 0.0075 to $<0.025$ & 0.83 & $0.70-0.99$ & 0.040 \\
\hline & 0.025 to $<0.075$ & 0.99 & $0.83-1.18$ & 0.922 \\
\hline & $>=0.075$ & 1.23 & $1.03-1.49$ & 0.025 \\
\hline
\end{tabular}


Figure 1: Kaplan-Meier curves calculated on time intervals from post-outbreak test to disease incident and stratified by increasing severity of disclosure bTB test.

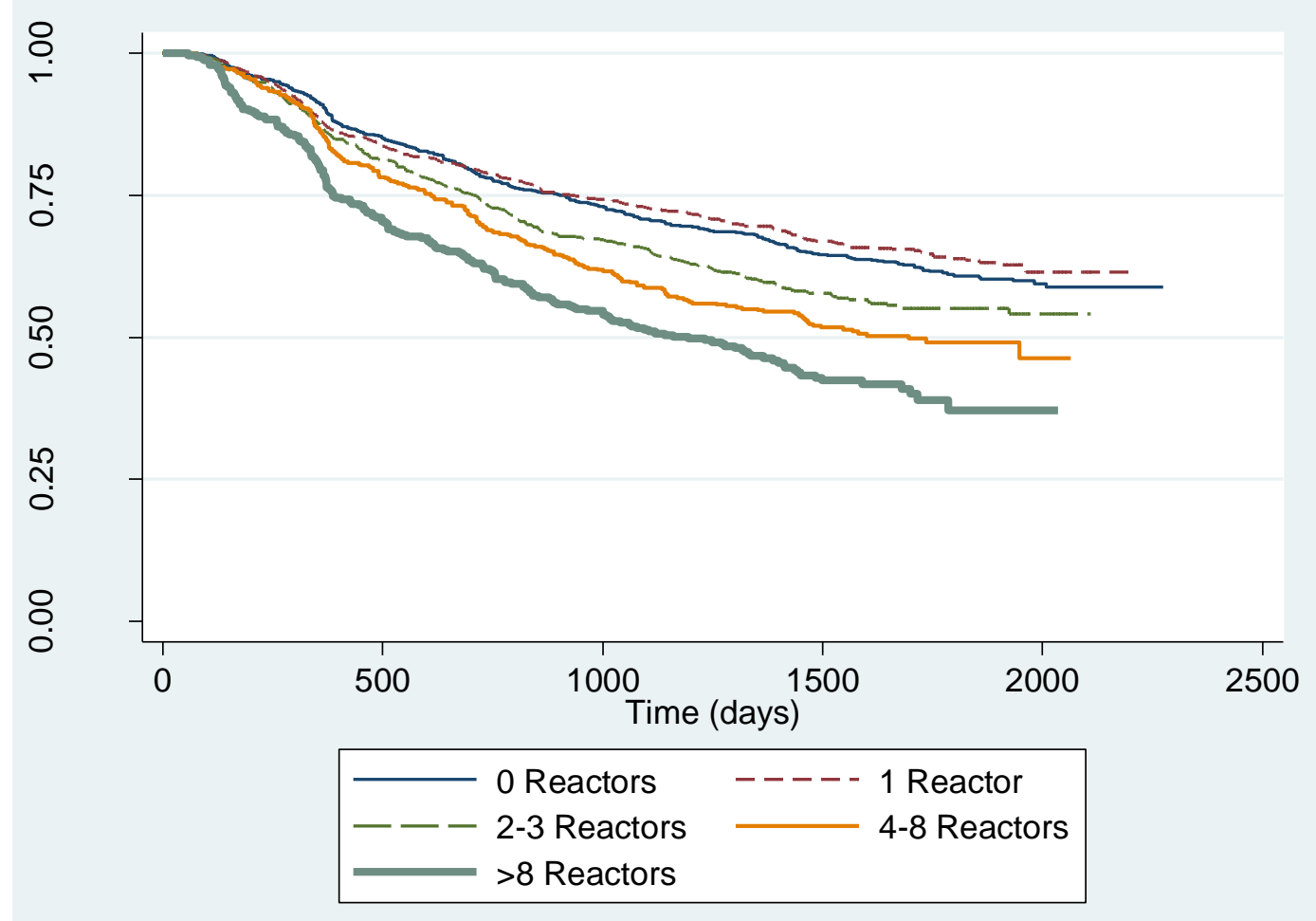


Figure 2: Kaplan-Meier curves calculated on time intervals from post-outbreak test to disease incident and stratified by increasing levels of local prevalence for bTB.

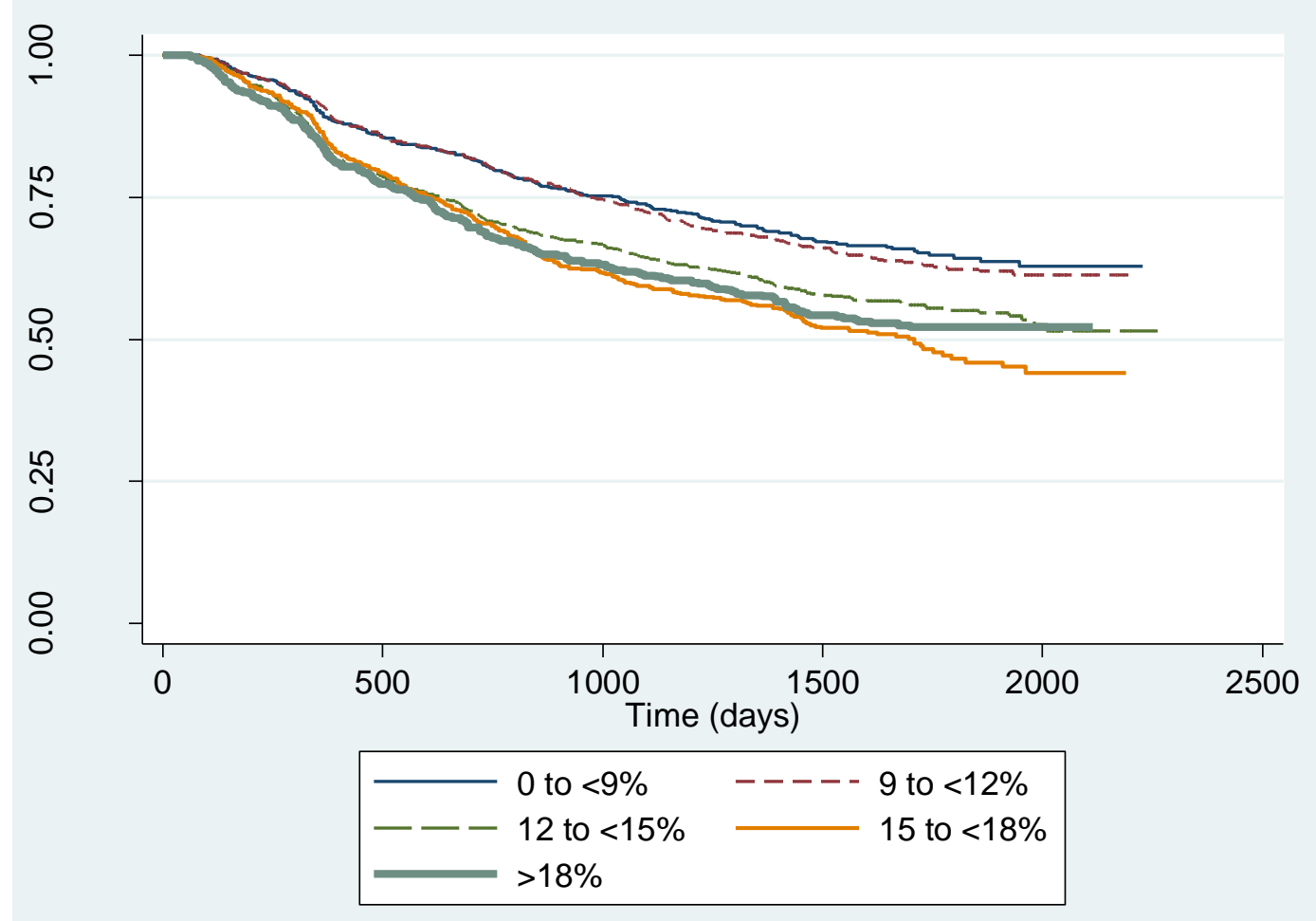


Figure 3: Kaplan-Meier curves calculated on time intervals from post-outbreak test to disease incident and stratified by increasing levels of purchase intensity.

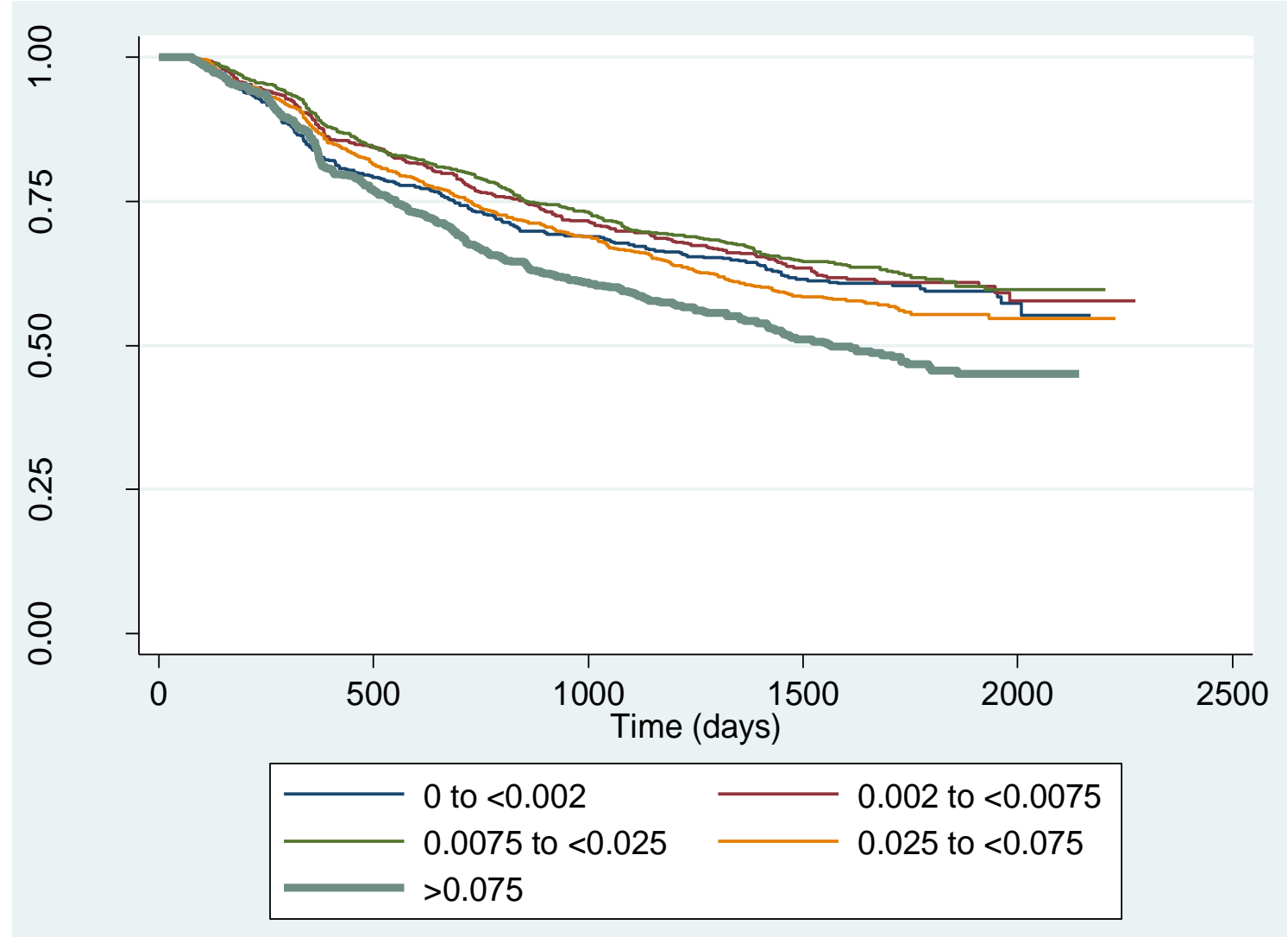


Figure 4: Kaplan-Meier curves calculated on time intervals from post-outbreak test to disease incident and stratified by increasing herd size.

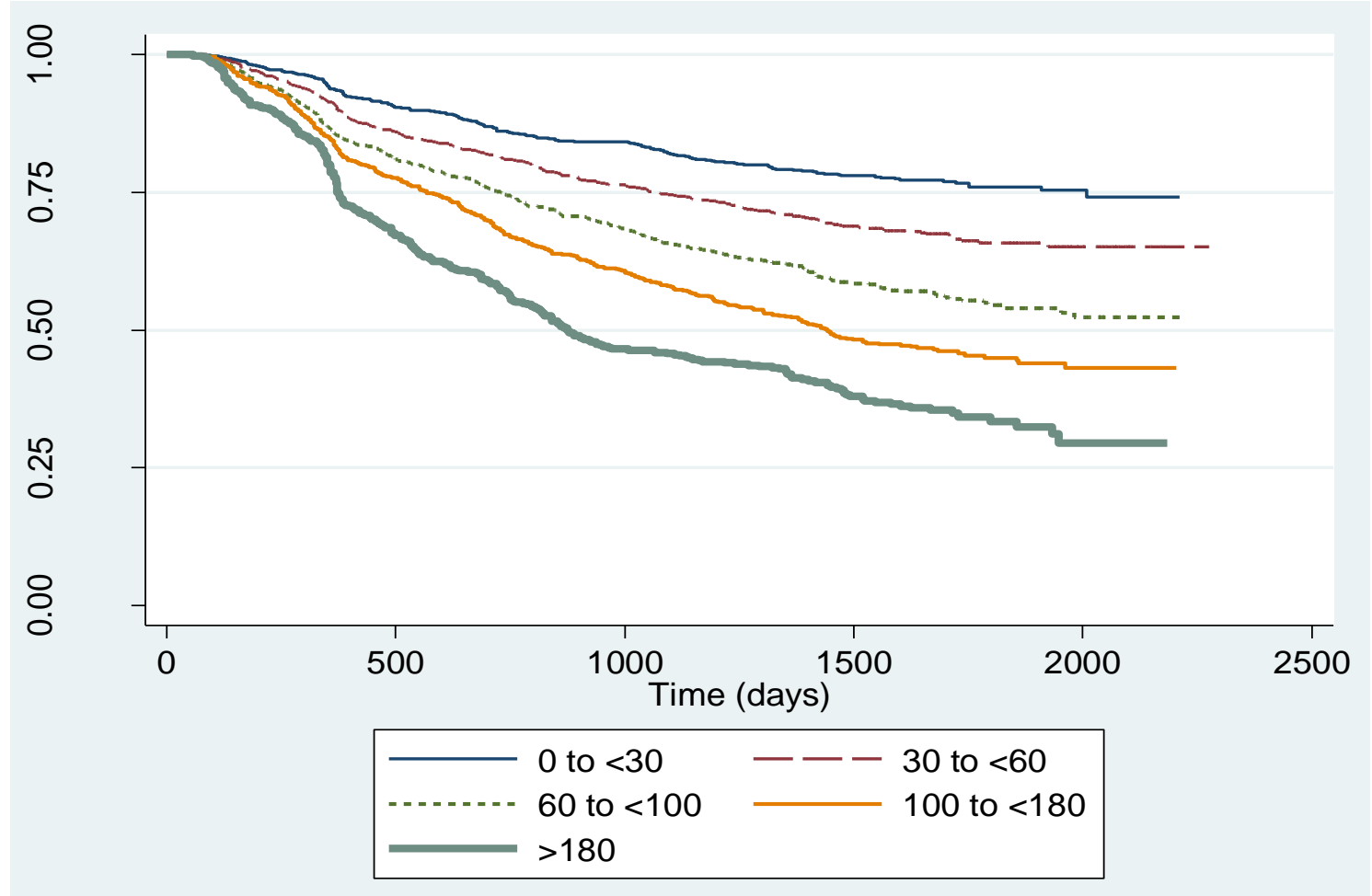


Figure 5: Kaplan-Meier curves calculated on time intervals from post-outbreak test to disease incident and stratified by whether a herd is non-dairy or dairy in nature.

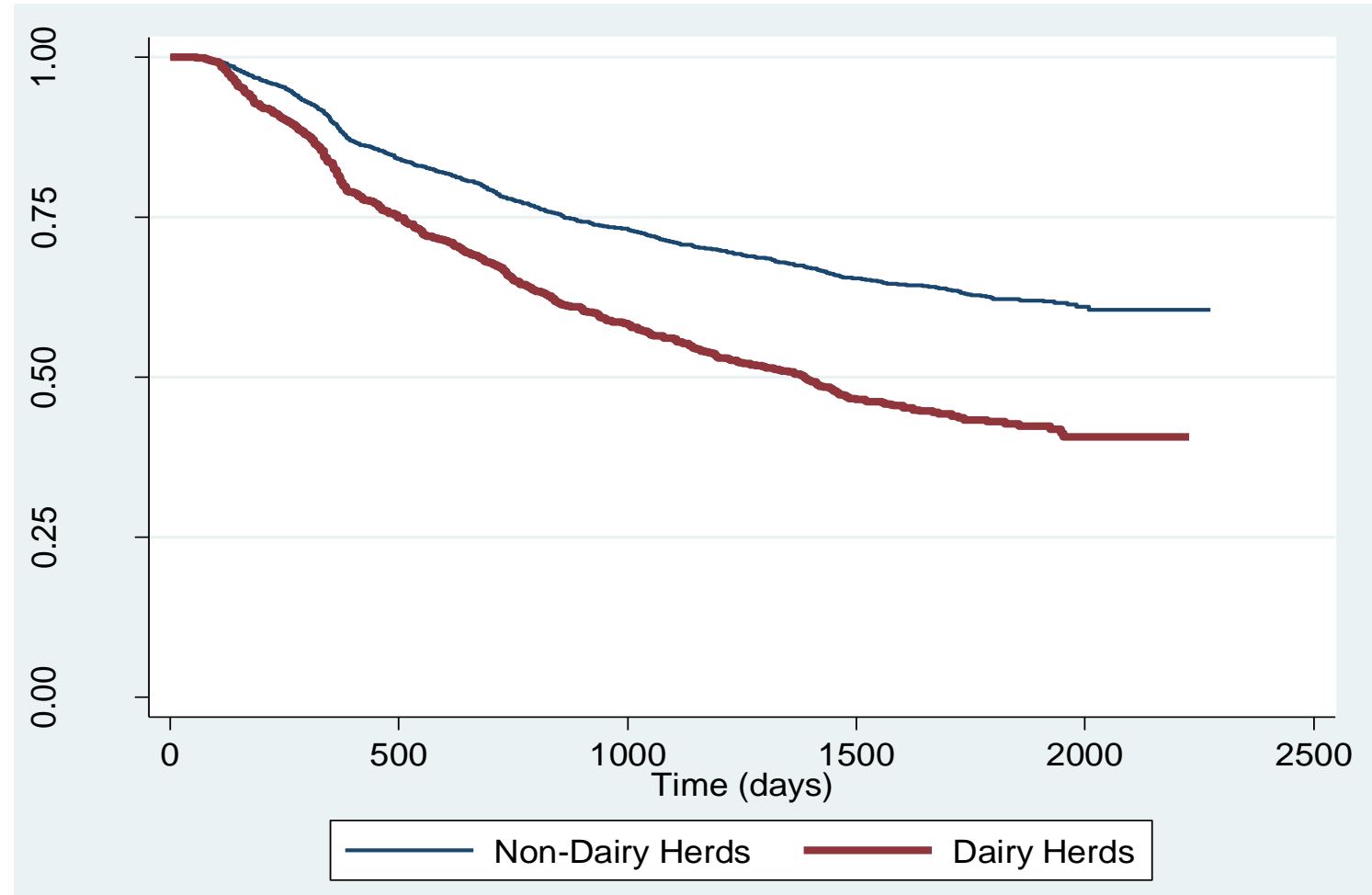


Figure 6: Kaplan-Meier curves calculated on time intervals from post-outbreak test to disease incident and stratified by bTB confirmation.

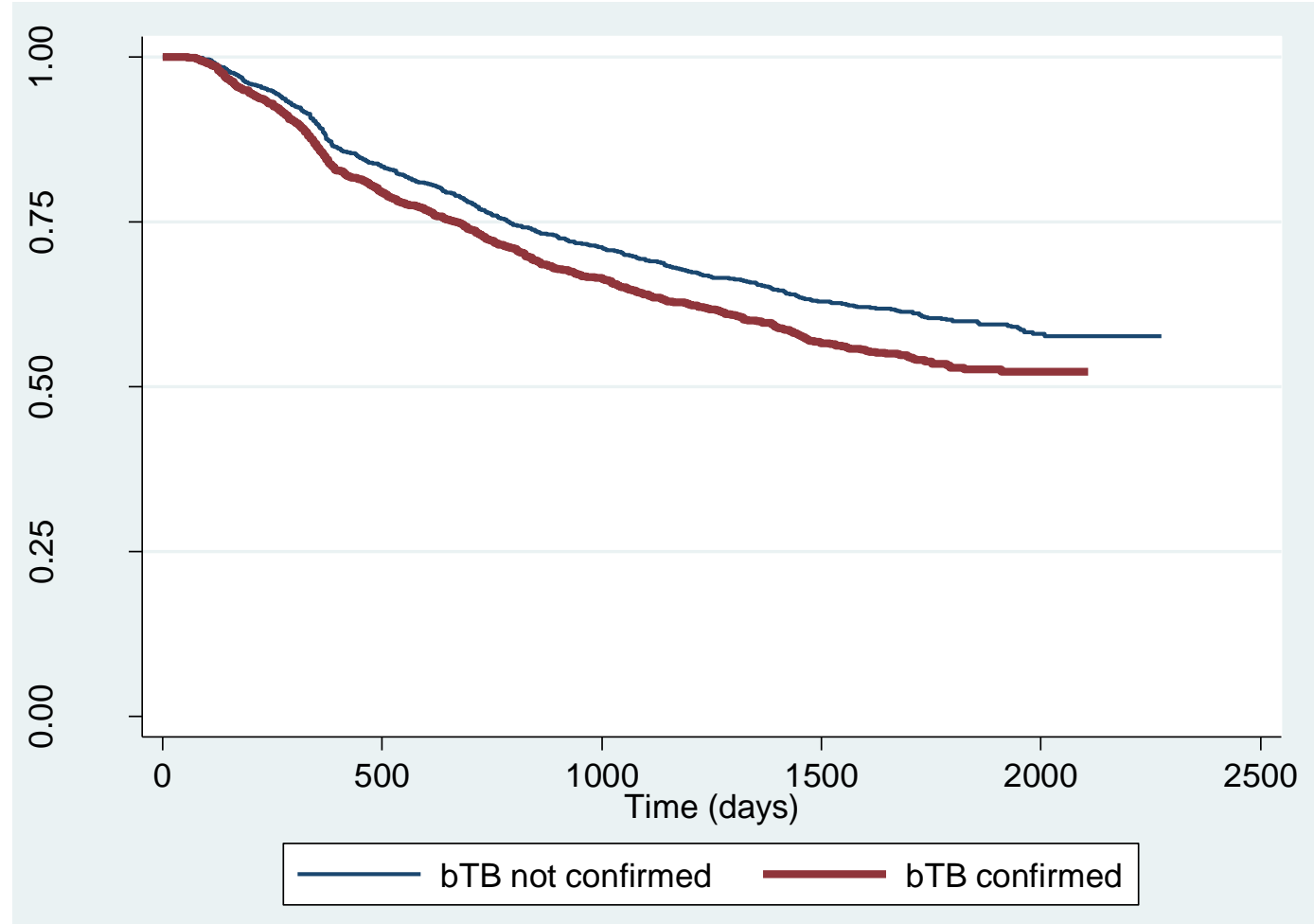

